The Journal of Animal \& Plant Sciences, 30(5): 2020, Page: 1254-1262

ISSN (print): 1018-7081; ISSN (online): 2309-8694

\title{
DETERMINANTS FOR THE ADOPTION OF TECHNOLOGY AND THE CHOICE OF MARKETING CHANNEL FOR RICE SMALLHOLDER FARMERS IN SOUTHEAST NIGERIA
}

\author{
A. B. Ezeibe ${ }^{1}$, P. I. Opata ${ }^{2}$ and C. O. Ume ${ }^{2}$ \\ ${ }^{1}$ Center for Entrepreneurship and Development Research, University of Nigeria, Nsukka \\ ${ }^{2}$ Agricultural Economics Department, University of Nigeria, Nsukka, Nigeria \\ "Corresponding author's E-mail: patience.opata@unn.edu.ng
}

\begin{abstract}
This article examines the factors that unravel how the smallholder rice farmers were influenced by contractual engagement and cooperative participation against spot marketing channels for the adoption of technology and market access using a sample of 420 rice farmers in south-east Nigeria. The multinomial logistic regression model was used and the findings of which reveal that age, land size, distance to market, the volume of long grain rice, fertilizer applied, agrochemicals, access to extension agent, distance to the asphalt road and belonging to farmers' association werefound as significant factors influencing the choice of marketing channels. Spot market predominates as the majority of farm households are still using spot market and there are still high transaction costs and other constraints. Creation of market linkages, technology and access to input and output markets by smallholders was found to be areas of intervention to improve the rice value chain and to mitigate high transaction costs and technology constraints.
\end{abstract}

Keywords: smallholders, cooperative, rice, market access, contract, technology.

https://doi.org/10.36899/JAPS.2020.5.0143

Published online June 25, 2020

\section{INTRODUCTION}

Rice (Oryza sativa) is generally regarded as one of the most important staple cereal crops in sub-Saharan Africa (SSA) with a huge potential for addressing the challenge of food insecurity (Saito et al., 2015; Niang et al., 2017). Rice is eaten by almost everybody in Nigeria and it represent basic food for more than 750 million persons in SSA in 2016 (Arouna et al., 2017). In 2016, demand for milled rice was 6.3 million metric tons while the supply was 2.3 million (Federal Ministry of Agriculture and Rural Development, 2016; Abbas etal.,2018). This suggests that Nigeria has to make up for rice production deficiency through the importation of at least 4 million tons of rice annually. The heavy reliance of Nigeria on food import leaves the local populations vulnerable to increased prices and volatility from international markets during crises as well as depletion of the nation's foreign reserves (Blanc et al., 2016; Abbas et al., 2018; Harris, 2018). Nigeria's Government spent a whooping sum of $\$ 2.41$ billion on rice importation between January 2012 and May 2015(Abbas et al., 2018). However, smallholder sector in Nigeria and other subSaharan Africa lack access to technology such as chemical fertilizers, improved seeds, agro-chemicals, technical guidance, other inputs and market outlets along the rice value chain, from production to consumption and these constraints increase the gap in rice supply and demand due to low productivity of rice (Saito et al.,
2015; Niang et al., 2017). Low productivity of rice also resulted from lack of information about how to use these technologies resulting in low adoption rate (Bernard et al., 2017).Other limiting factors in the rice value chains are lack of access to credit and choice of market outlet. Choice of marketing channels for rice is affected by information asymmetry, transaction costs and other institutional factors (Alemu, 2015; Jagwe and Machethe, 2016; Ebata et al., 2017). Thus lack of input and output markets affect rice producers' value chains and prevent them from market-oriented production(Alemu, 2015; Du et al., 2016; Ebata et al., 2017).Various constraints of rice farmers along the value chain could be reduced by choosing among contract, cooperative or spot markets.

Spot marketing are traditional methods of business relationships that involve a large number of buyers and sellers who meet at a certain time and place. Spot market transactions offer independence to producers in decision making and they involve no costs or profitsharing as all production costs incurred or profits generated through the production and sale are borne by the producer. A contract involves an agreement between a seller and a buyer which stipulates prices, quantity and quality for a commodity to be delivered at a later time (Mishra et al., 2018).This can be a resource-providing contract which involves the provision of farm technology and credit by contractors to the farmers. It can also be a marketing contract which help farmers to reduce price and income risks and improve access to markets(Ochieng et al., 2017). Cooperatives carry out collection, storing, 
cooling, processing, and distribution of agricultural produce the aim is to add value to products and improve gains to famer members. Besides, farmers favor and trust cooperatives, and they facilitate technology adoption (Chagwiza et al., 2016; Wossen et al., 2017)

Within the promotion of the performance of the rice marketing system in Nigeria, a proper understanding of the factors influencing the adoption of technology and the choice of marketing channels between contract, cooperative and spot market is necessary for research, development and policy. Several studies have investigated factors affecting the selection of marketing channels or those affecting volume of sales through the use of spot market as well as structure conduct and performance of spot marketing system (Jagwe and Machethe, 2016; Bernard et al., 2017; Ebata and Hernandez, 2017; Chandio and Jiang, 2018; Opata, 2018). Some point to the problems of structure conduct and performance of various staple food markets while others show significant effect of personal, asset capital, institutional, technological and socio-economic factors on volume of sale or choice of marketing channels in spot market. Existing research echoes the question of why spot marketing systems of rice are not performing well pointing to low input use and stagnated agricultural productivity (Jagwe and Machethe, 2016; Bernard et al., 2017). Effective marketing channels and adoption of technology require an appropriate solution to the various constraints encountered by farmers along the rice value chains from production to consumption in Nigeria. Cooperative and contract engagement could be the solution to technology adoption and access to markets since they assist farmers in input and output markets. Unlike previous empirical studies in southeast Nigeria, our interest and objective in this paper is to understand the determinants for adoption of technology and choice of marketing channel in the context of contract and cooperative channels compared to spot marketing for rice smallholder farmers. This is the focus of this paper. This is essential for identifying the factors that can transform rice sector to market oriented production.

\section{MATERIALS AND METHODS}

Study area: The study area is South-east geopolitical zone of Nigeria. Five states constitute this zone: Abia, Anambra, Ebonyi, Enugu, and Imo, covering latitude $4^{0}$ $50^{\prime} \mathrm{N}$ to $7^{0} 10^{\prime} \mathrm{N}$ and longitudes $6^{\circ} 40^{\prime} \mathrm{E}$ to $8^{0} 30^{\prime} \mathrm{E}$. The zone spreads over a total area of $78,618 \mathrm{~km}^{2}$, representing $8.5 \%$ of the nation's total land area. The area has aprojected total population of 16381729 (World Meters, 2019).

Sampling, the validity of measurement and data collection: There are four-stage simple random sampling techniques. The first stage was the selection of statesthrough random sampling techniques and this gave rise to two states Enugu and Abia. The second stage was the selection of Local government Areas (LGAs), six LGAs areas were selected from each state to give a random sample of twelve LGAs. The third stage was the selection of communities. Two communities were randomly selected from each LGAs to give a sample of twenty-four communities while the fourth stage was the selection of respondents from the communities. A total of four hundred and twenty households engaged in rice farming were randomly selected from the communities for the study.

Cross-sectional data were generated from a farmed survey conducted during 2017/18 crop year, and primarily involved administration of sets of structured questionnaires to respondents, including using openended questionnaires for focus group discussions. The survey questionnaire was duly pre-tested on a randomly selected sample of 26 respondents, in January 2017. This was subsequently followed by a pilot survey of 100 farmers (50 men and 50 women), exploring the potentials and limitations of the study. The result of the pre-test and pilot study was used in validating the survey questionnaire coverage, timing, and administration techniques adopted.

Analytical framework and Empirical Model: Smallholder market behavior in the context of rice produce marketing can be understood by examining choices of a marketing channel for output market in a constraint utility optimization framework where an individual is assumed to maximize market participation in terms of market channel selection subject to a set of socio-economic and institutional constraints. The framework is couched around market channels (channel 1 , channel 2, and channel 3) in a market environment where transactions on varying quantities of rice take place. Producers in this context are categorized based on their selection for either channel 1 denoting contract or channel 2 denoting cooperatives or channel 3 spot market, and also depending on their inherent marketing goals, including socio-economic and institutional characteristics that influence their choices. Market channel choice decision is presented in the frame of a Multinomial logit regression model. Here the dependent variables are defined to have three possible conditional (choice) probabilities across channel 1 , channel 2 and channel 3 (i.e. the three-channel choice used in this study). The conceptual foundation for choice models is often appropriate for modeling discrete choice decisions such as the case of this study. In the implementation model, market channel choices are modeled with a three equation system. Thus a set of coefficients $\beta^{(1)}, \beta^{(2)}, \beta^{(3)}$, corresponding to three possible options step $1,2,3$ in marketing channels can be estimated as: 
$\operatorname{Pr}(Z=1) \frac{e^{x \beta(1)}}{e^{x \beta(1)}+e^{x \beta(2)}+e^{x \beta(3)}}$

$\operatorname{Pr}(Z=2) \frac{e^{x \beta(2)}}{e^{x \beta(1)}+e^{x \beta(2)}+e^{x \beta(3)}}$

$\operatorname{Pr}(Z=3) \frac{e^{x \beta(3)}}{e^{x \beta(1)}+e^{x \beta(2)}+e^{x \beta(3)}}$

The model, however, is unidentified in the sense that there is more than one solution of $\beta^{(1)}, \beta^{(2)}, \beta^{(3)}$, that lead to the same probabilities for $Z=1, Z=2$, and $Z=3$. To identify the model, one of $\beta^{(1)}, \beta^{(2)}, \beta^{(3)}$ is arbitrarily set to zero. That is if we set $\beta^{(3)}=0$ the remaining coefficient $\beta^{(1)}, \beta^{(2)}$, would measure the change in relative to the $Z=$ 3 group. In other words, we would be comparing the most vertically differentiated channel (3) with the less differentiated ones ( 1 and 2$)$. Then setting $\beta^{(3)}=0$, the above equations (1) to (3) become:

$\operatorname{Pr}(Z=1) \frac{e^{x \beta(1)}}{e^{x \beta(1)}+e^{x \beta(2)}+1}$

$\operatorname{Pr}(Z=2) \frac{e^{x \beta(2)}}{e^{x \beta(1)}+e^{x \beta(2)}+1}$

$\operatorname{Pr}(Z=3) \frac{e^{x \beta(3)}}{e^{x \beta(1)}+e^{x \beta(2)}+1}$

The relative probability of $Z=1$ to the base category is given as:

$\frac{\operatorname{Pr}(Z=1)}{\operatorname{Pr}(Z=3)}=e^{x \beta(1)}$

If we call this the relative likelihood and assume that $X$ and $\beta_{\mathrm{k}}^{(1)}$ are vectors equal to $\left(X_{1}, X_{2}, X_{3} \ldots X_{k}\right)$ and $\left(\beta_{1}{ }^{(1)} \beta_{2}{ }^{(1)} \ldots \ldots . \beta_{\mathrm{k}}{ }^{(1)}\right.$ respectively. The ratio of relative likelihood for one unit change in $X_{1}$ relative to the base category is then:

$\frac{e^{\beta_{1}^{(1)}} X_{1}+\ldots+\beta_{1}^{(1)}\left(X_{1}+1\right)+\ldots+\beta_{k}^{(1)} X_{K}}{e^{\beta(1)} X_{1}+\ldots \beta_{1}^{(1)} X_{1}+\ldots+\beta_{k}^{(1)} X_{k}}=e^{\beta^{(1)}}$

Therefore the exponential value of a coefficient is the relative likelihood ratio for a unit change in the corresponding variable as reported by Opata, (2018)considering that producers make decisions regarding which buyers for selling their production (for example contracts in channel step 1; cooperatives in channel step 2 or spot market in channel step 3). Thus if $Z_{1}, Z_{2}, Z_{3}$ are the dependent variables representing (channel step 1), which denotes channels where the farmer sells directly to the contractor; (channel step 2), denoting channels where farmer sell directly to the cooperatives; and (channel step 3), which denotes channels where the farmer sell his or her product in the spot market. The latter category is where the smallholder incurs transaction costs and the marketing channel has vertically differentiated into specialized functions like wholesale and retail. Then Multinomial logit model will be fitted to test how dependent variables: step1, step 2 and step 3 channels can be explained by some independent variable xjs.

The empirical model: The independent variables are the following socio-economic factors that were hypothesized as possible determinants of the producers' choice of contract engagement, cooperatives or spot market channel.

$Z_{1}=F\left(X_{1}, X_{2}, X_{3}, X_{4}, X_{5}, X_{6}, X_{7} \ldots \ldots X_{16 .}\right)+\mu \ldots(9)$

$Z_{2}=F\left(X_{1}, X_{2}, X_{3}, X_{4}, X_{5}, X_{6}, X_{7} \ldots \ldots X_{16}\right)+\mu \ldots(10)$

$Z_{3}=F\left(X_{1}, X_{2}, X_{3}, X_{4}, X_{5}, X_{6}, X_{7} \ldots \ldots . . X_{16}\right)+\mu \ldots(11)$

The variables and expected signs are as follows:

Independent variables and the expected sign: The choice of cooperative and contract channel options for sale of output of farmers compared to spot market transactions is expected to improve the technology and market access of smallholders. These private institutions (contractors or cooperatives) assist the smallholders by providing high-quality rice seeds variety such as long rice grain or Nerica, a variety developed specifically for Africa, credit access, agrochemicals and pre and postemergence herbicides to them as well as buying back their output of rice.

The contractors engage smallholders to provide input and output market and therefore the income of farmers from crop production is expected to increase as a result of contract engagement. An increase in income is from a reduction in transaction costs resulting from searching for market information as they have already secured market. Welfare of smallholders in terms of human and asset capital of the farmer (sex, age, education, active family size, land size), market characteristics (variety of rice for the market, distance to market), institutions and infrastructure (access to asphalt roads and participation in rural institutions), technology requirement (pre-emergence herbicides, postemergence herbicides, insecticides, fungicides, rodenticides, $75 \mathrm{Hp}$ tractor, knapsack sprayer, boom sprayer, fertiliser, use of Faro 44, 52, Nerica or long-grain rice varieties, herbicides), and networks/social capital (knowledge of extension agents (EAs), membership of farmers' associations) is also expected to improve by selection of contract engagement or cooperative marketing channels. 
Table 1. Summary of independent variables and the expected sign.

\begin{tabular}{lcc}
\hline Variables & \multicolumn{2}{c}{$\begin{array}{c}\text { Expected sign in relation to spot market is negative } \\
\text { when contract or cooperative is positive }\end{array}$} \\
\cline { 2 - 3 } & Contract & Cooperative \\
\hline Human and asset capital & & + \\
Gender of the household head (GHH) & +- & + \\
Age of the household head (AHH) & + & + \\
Education of the household head (EHH) & + & - \\
Number of the active family member (FS) & + & + \\
Land size in Ha (LS) & + & + \\
Market & + & + \\
Distance to the market in km (MKD) & & + \\
The volume of long grain rice in kg (VOL) & + & + \\
Technology & - & + \\
Fertilizer & + & + \\
Faro 44 or Faro 52 & + & + \\
Nerica or long grain rice & + & + \\
Seed treatment chemical & + & + \\
Herbicides (Pre-emergence, post-emergence) & & + \\
Other agrochemicals (insecticides, fungicides, rodenticides) & + & + \\
Institutional infrastructure and network & + & + \\
Distance to asphalt road km (RDD) & + & + \\
Access to extension agent (EXA) & & \\
Farmers association (FG) & & + \\
\hline
\end{tabular}

Field survey, 2017 (Characters in parenthesis are the symbols of the variables)

No sign could be expected apriorito gender concerning contract engagement compare to the spot market, however, gender is expected to be positively related to cooperative participation concerning spot market transaction. Gender is allocated dummy value where the gender of households took the value of one if the household head is a male and zero otherwise The expected effect of years of formal education is that those educated household head will have better knowledge and skill in making an informed decision especially concerning choice of cooperatives than those with less education. Education is also expected to be positively related to contract engagement as the contractors will more likely relate to those who are educated and skilled in keeping the terms of the agreement. Education is captured with the number of years of formal schooling and it is a continuous variable. The age of the household head is measured in years. This variable has the ambiguous expectation, on one hand, we expect that as farmer ages he or she has more experience and skills in the problems affecting the marketing of output and thus will join cooperative or operate under contract. On the other hand, younger farmers may operate under cooperative to get the loan and other input or output more than old farmers. Family size is captured by the number of adult members in the house and it is a continuous variable. This variable will positively influence more volume of production and this will likely influence farmers preference for contract or cooperative for the assured market for rice output relative to spot market transaction. Land size is measured in hectares and is a continuous variable and is expected to be positively related to contract or cooperative and negative with the spot market.

The market situation is captured in terms of the amount of long rice grain or Nerica variety produced and the distance the household is located from the district market. Those with large quantities of long rice grain FARO 66 and 67 or Nerica and who are located at a far distance from the market may be affected by market access and will prefer cooperative and contract for selling their output compared to spot market transactions. The variables that were used to capture institutional infrastructure, as well as social capital, contact with extension agent for accessing technical information, membership of farmers group and distance to the asphalt road. Technology requirement is captured in terms of households' demands for farm technology such as fertilizer, herbicides, pesticides, and long grain rice and other input. Those who need more technology are expected to enter into contracts or engage in cooperatives.

\section{RESULTS AND DISCUSSION}

Farm and sample household characteristics: Table 2 shows that there are three types of marketing channels 
from where producers of rice could select to market their rice output (spot market, contract and cooperatives). Spot market predominates as most $(83.34 \%)$ of the rice producers engage in spot markets while $8.56 \%$ and $8.10 \%$ selected contracts and cooperatives respectively.

Table 2. Coordination mechanisms used by rice producer in marketing.

\begin{tabular}{lcc}
\hline \multirow{2}{*}{ Coordination types } & \multicolumn{2}{c}{ Rice producers } \\
Number & Percentage \\
\hline Spot market & 350 & 83.34 \\
Contract & 36 & 8.56 \\
Cooperatives & 34 & 8.10 \\
Total & 420 & 100.00 \\
\hline
\end{tabular}

Field survey, 2017.

Summary statistics of rice producers' demographic and economic characteristics: Tables 3 shows the characteristics of farmers who engage in contract, participate in cooperative and or transact through spot market in terms of mean and standard deviation of age, gender, education, active family members, land size, distance to market, volume of latest improved rice seed, fertilizers as well as other institutional factors.

The table shows that rice farmers that are engaged in contract used a higher volume of fertilizer $(550 \mathrm{~kg})$ while those that participate in cooperative applied $450 \mathrm{~kg}$ and the minimum was used by those involved in spot market transactions $(350 \mathrm{~kg})$ fertilizer. Looking at the distance from the asphalt road from the farmer, it reveals that those involved in cooperative and contract were located further from the asphalt road. The distance is 28.56 for cooperatives, $25.50 \mathrm{~km}$ for contact and $18.56 \mathrm{~km}$ for spot market showing that those engaged in spot market transaction has the highest access to the market. About $(67 \%)$ of the cooperative rice producers have access to extension service; $73 \%$ of the contracting rice producers have access to extension service and $45 \%$ of the spot operating rice producers have access to extension service. Similarly, about $61 \%$ of the cooperative rice producers are members of farmers' organization while $81 \%$ of those that are engaged in the contract are members of farmers group and 69 per cent of those that use spot market are members of farmers group.

Table 3. Summary statistics of rice producers' demographic and economic characteristics.

\begin{tabular}{|c|c|c|c|c|c|c|}
\hline \multirow[t]{2}{*}{ Variables } & \multicolumn{2}{|c|}{ Cooperatives } & \multicolumn{2}{|c|}{ Contract } & \multicolumn{2}{|c|}{ Spot market } \\
\hline & Mean & SD & Mean & SD & Mean & SD \\
\hline \multicolumn{7}{|l|}{ Human and asset capital } \\
\hline Gender of the household head (GHH) & 0.73 & 0.41 & 0.91 & 0.19 & 0.91 & 0.12 \\
\hline Age of the household head (AHH) & 45.87 & 7.61 & 39.12 & 5.05 & 48.21 & 6.94 \\
\hline Education of the household head (EHH) & 10.89 & 8.10 & 12.03 & 1.98 & 9.10 & 3.10 \\
\hline Number of the active family member (FS) & 3.34 & 1.34 & 2. 09 & 0.91 & 2.01 & 0.56 \\
\hline Land size in $\mathrm{Ha}$ (LS) & 2.15 & 2.31 & 1.89 & 0.71 & 2.55 & 1.23 \\
\hline \multicolumn{7}{|l|}{ Market } \\
\hline Distance to the market in km (MKD) & 18.96 & 9.66 & 24.78 & 9.91 & 16.23 & 3.55 \\
\hline The volume of long grain rice in tons (VOL) & 2.13 & 0.73 & 1.95 & 0.43 & 1.98 & 5.44 \\
\hline \multicolumn{7}{|l|}{ Technology } \\
\hline Fertilizer in $\mathrm{kg}$ & 450 & 250 & 550 & 150 & 350 & 200 \\
\hline Faro 44 or Faro 52 in tons & 1.25 & 0.89 & 1.36 & 0.56 & 1.75 & 0.23 \\
\hline Nerica or long grain rice in tons & 0.90 & 1.52 & 0.49 & 0.13 & 0.20 & 0.09 \\
\hline Seed treatment chemical in $\mathrm{mg}$ & 250 & 150 & 375 & 156 & 55.08 & 17.0 \\
\hline Herbicides (Pre-emergence, post-emergence) & 8.00 & 0.12 & 8.00 & 0.15 & 0.78 & 0.20 \\
\hline $\begin{array}{l}\text { Other agrochemicals (insecticides, fungicides, rodenticides) } \\
\text { in liters }\end{array}$ & 10.00 & 0.50 & 9.50 & 0.10 & 12.25 & 1.67 \\
\hline \multicolumn{7}{|l|}{ Institutional infrastructure and network } \\
\hline Distance to asphalt road km (RDD) & 28.56 & 12.2 & 25.5 & 6.55 & 18.56 & 3.46 \\
\hline Access to extension agent (EXA) & 0.67 & 0.18 & 0.73 & 0.11 & 0.45 & 0.21 \\
\hline Farmers association $(\mathrm{FG})$ & 0.61 & 0.23 & 0.81 & 0.21 & 0.69 & 0.17 \\
\hline
\end{tabular}

Field survey 2017

Diagnostic test for Multinomial Logit and correlation coefficient of some variables: Before subjecting data for multinomial logit analysis, several econometric issues needed to be addressed before estimation. The pair-wise correlations among independent variables were examined to find out those variables that will affect the model. The independent variables that can affect the model were removed from the model. This also eliminates potential multicollinearity among explanatory variables. An 
analysis of the variance inflation factor (VIF) did not also show any problem.

The assumption of independence is critical and leads to substantial computational difficulties involving in the computation of multivariate integrals. If there is a change in the characteristics of any other alternative in the choice set, this property requires that the two probabilities must adjust precisely to preserve their initial ratio, that is, the percentage change in each probability must adjust precisely to preserve their initial ratio, that is, the percentage change in each probability should be equal. The independence of irrelevant alternatives (IIA) specification test for models was conducted to check whether the ratio of the probabilities of choosing any two alternatives is independent of the attributes of any other alternative in the choice set. The test indicates that the difference in the coefficients is not systematic and the ratio of the probability of choosing contracts from spot markets is independent of the attributes of cooperatives and therefore no need of using nested logit as an alternative.

\section{Multinomial Logistic Regression Analysis: A} multinomial logistic regression model was run to determine the significant variables that drive farmers to engage in contracts or cooperatives against spot market transactions. The variables in Table 4 were considered and tested for their significance. The multinomial logistic results of contract (channel step 1) i.e. farmers engaged with a contractor for output market before going into production; (channel step 2) i.e. producers are participating in a cooperative that sponsored selling and distribute input before going into production; as compared with spot market (channel step 3) i.e rice farmers sell rice in the spot market and incur transaction costs and this is the baseline group as presented in Table 4. Table 4 shows the estimated coefficients ( $\beta$ values), standard error, and significant values $(\mathrm{P})$ of independent variables in the model.

The estimated coefficients ( $\beta$ values) measure the expected change in the logit for a unit change in each independent variable, all other independent variables being constant. The sign of the coefficient shows the direction of the influence of the variable on the logit. It follows that a positive value indicates an increase in the likelihood that a household will change to the alternative option for the baseline group. A negative value shows that it is less likely that a household will consider the alternative. Therefore, in this study, a positive value in contract implies an increase in the likelihood of remaining in contract engagement.

The significant values (also known as the pvalue) show whether a change in the independent variable significantly influences the logit at a given level. In other words, the degree to which choosing channel step 1, step 2 or 3 can be explained by household heads' human and asset capital, market characteristics, technology, and institutional infrastructure and network. In this study, the variables were tested at $1 \%, 5 \%$ and $10 \%$ significant levels. Thus, if the significant value is greater than 0.01 , 0.05 , and 0.1 then it shows that there is insufficient evidence to support that the independent variable influences a change away from the baseline group. If the significant value is equal or less than 0.01 or 0.05 and 0.10 , then there is enough evidence to support a claim presented by the coefficient value. The standard error in the value measures the standard deviation of the error in the value of a given variable.

The marginal effects of the multinomial logistic regression model are presented in Table 4. Rice producers' choice of contracting or cooperative engagements or spot market depends on market, technology, infrastructural, human asset capital and network-related factors.

From the results in Table 4, based on the multinomial logit model used, the $\mathrm{R}^{2}$ value of the model is 0.873 implying that the independent variables in the model explained about $87 \%$ of the variability in the choice of marketing channels.

The model showed that in comparison with contract engagement against spot market transaction, human and asset capital, specifically the age of household head positively influenced farmers in contract engagement. One year increase in the age of farmers increased the probability of contracting by 3 percent and it is significant at 5\% level. Similarly, age positively influenced farmers' participation in cooperative against spot market transaction and it is 4.3 percent and $1 \%$ significant level. This implies that a year increase in farmers' age increases the probability to be a member of cooperative by 4.3 percent. This is contrary to aprioriexpectation as younger farmers were expected to participate in cooperative and to engage in contract compare to the spot market.

Land size also positively influencing farmers to engage in the spot market against contract engagement and 1ha increase in the size of land increases the probability to transact through spot market against contract by 9 percent and it is significant at $1 \%$. The numbers of active family members are negative and significant factors influencing cooperative engagements of farmers. Thus if the number of active family members increases by one, then there will be $6.8 \%$ increase in the number of farmers that will change to spot market and it is significant at 5\% level.

In comparison with contract engagement against transaction through the spot market, market characteristics, specifically, a longer distance to market positively influenced the volume of rice marketed by farmers. The results indicate that being one kilometer farther away from the market increases the probability of rice farmers to contract by 6.3 percent and significant at the $5 \%$ level. However, the distance to the market 
negatively influences cooperative engagement and the farmers are found changing to the baseline if the distance increases i.e. to sports market transactions. One kilometer increase in distance increases spot market transactions by 4.1 percent and significant at the 5\% level. Many of the farmers are smallholders who lack market power as they offer small amounts to the market. Thus they pool rice and sell collectively, it may reduce competition among them and give market power to influence prices. The volume of rice produced by rice farmers also positively influenced him or her to contract engagement. Farmers secure the market before going into the large volume of rice production. A one-kilogram increase in the volume of rice for sale in the market increases the probability of rice farmers to contract by 9.6 percent at the $1 \%$ significance level. However, an increase in the volume of rice negatively influenced the rice farmers to cooperative engagement by 3.8 percent significant at the $1 \%$ level. This implies that a high volume of rice products influenced farmers towards spot transactions rather than cooperatives participation.

Table 4. Multinomial Logistic regression result for determinants of rice market choice.

\begin{tabular}{|c|c|c|c|c|c|}
\hline \multirow[t]{2}{*}{ Variables } & & \multicolumn{2}{|c|}{ Contract participation } & \multicolumn{2}{|c|}{ Cooperative engagement } \\
\hline & & Coefficient & (p) & Coefficient & \\
\hline \multicolumn{6}{|l|}{ Human and asset capital } \\
\hline Gender of the household head (GHH) & & $5.023(10.08)$ & 0.251 & $-0.12(0.054)$ & -1.03 \\
\hline Age of the household head (AHH) & & $0.035(0.01)$ & $0.001^{* * *}$ & $0.043(0.01)$ & $0.002^{* * *}$ \\
\hline Education of the household head (EHH) & & $0.030(0.06)$ & 0.103 & $0.663(0.004)$ & 0.321 \\
\hline Number of the active family member (FS) & & $0.007(0.015)$ & 0.234 & $-0.068(0.02)$ & $0.011^{* *}$ \\
\hline Land size in $\mathrm{Ha}(\mathrm{LS})$ & & $-0.09(0.023)$ & $0.002^{* * *}$ & $0.034(0.45)$ & 0.105 \\
\hline \multicolumn{6}{|l|}{ Market } \\
\hline Distance to the market in km (MKD) & & $0.0633(0.01)$ & $0.012^{* *}$ & $-0.041(0.01)$ & $0.043^{* *}$ \\
\hline The volume of long grain rice in tons (VOL) & & $0.096(0.003)$ & $0.001^{* * *}$ & $0.038(0.002)$ & $0.008^{* * *}$ \\
\hline \multicolumn{6}{|l|}{ Technology } \\
\hline Fertilizer in kg (FERT) & & $0.081(0.002)$ & $0.004^{* * *}$ & $0.076(0.003)$ & $0.009^{* * *}$ \\
\hline Faro 44 or Faro 52 in tons (FARO) & & $-0.095(0.01)$ & $0.002^{* * *}$ & $-0.05(0.003)$ & $0.007^{* * *}$ \\
\hline Nerica or long-grain F 66 in tons (NER) & & $0.145(0.02)$ & $0.056^{*}$ & $0.134(0.05)$ & 0.73 \\
\hline Seed treatment chemical in mg (SEED) & & $0.234(0.34)$ & 0.74 & $0.045(0.05)$ & 0.45 \\
\hline \multicolumn{6}{|l|}{ Herbicides (Pre-emergence, post-emergence) } \\
\hline \multirow{2}{*}{$\begin{array}{l}\text { Other agrochemicals (insecticides, } \\
\text { rodenticides) in liters (CHEM) }\end{array}$} & fungicides, & $0.025(0.35)$ & 0.45 & $0.045(0.34)$ & 0.32 \\
\hline & & $0.045(0.56)$ & $0.035^{* *}$ & $0.043(0.01)$ & $0.051^{*}$ \\
\hline \multirow{2}{*}{\multicolumn{6}{|c|}{ Institutional infrastructure and network }} \\
\hline & & & & & Distance to asphalt road km (RDD) \\
\hline Access to extension agent (EXA) & & $0.056(0.003)$ & $0.001^{* * *}$ & $0.065(0.023)$ & $0.034^{* *}$ \\
\hline Farmers association $(\mathrm{FG})$ & & $0.076(0.125)$ & 0.167 & $0.053(0.013)$ & $0.043^{* *}$ \\
\hline \multirow{2}{*}{\multicolumn{2}{|c|}{ Cons }} & $0.075(0.003)$ & $0.056^{*}$ & $-0.04(0.015)$ & $0.032^{* *}$ \\
\hline & & 2. $938(11.04)$ & $0.006^{* * *}$ & $6.78(0.873)$ & 0.262 \\
\hline
\end{tabular}

Value in brackets are standard errors; chi-square $<0.001$; No of obs $=420 ; \mathrm{R}^{2}=0.873$

${ }^{* * *},{ }^{* *},{ }^{*}$, Significant at the $1,5,10 \%$ significant level

In comparison with spot market transactions, technology requirements of rice farmers also drive them to contract and cooperative engagement. The need for fertilizer influence farmers to contract and participate in the cooperative. One kilogram increase in the need for fertilizer by rice farmers would increase the probability to contract by 8.1 percent, significant at the $1 \%$ level compared with spot market transactions. The demand for fertilizer will also increase the probability of cooperative participation by $7.6 \%$ and significant at $1 \%$. This implies that contract and cooperative engagement can serve as a source of technology acquisition for smallholders in rural
Nigeria. Longer grain FARO 66 and 67 and NERICA are positively related to contract engagement against spot market transactions by $14.5 \%$ and significant at $10 \%$. The longer grain rice variety is positive but not significant in cooperative engagement. Other improved varieties FARO 44 and 52 are negatively related to cooperative and contract engagement and therefore those varieties increase the probability of farmers to engage in spot market transactions against cooperative and contract transactions. They increase the probability to engage in spot market transactions by 9.5 percent compared with the contract engagement and 5\% compared with 
cooperatives participation and they are both significant at the $1 \%$ level. Using pesticides and fertilizer may imply financial constraint rice farmers, as fertilizer and pesticides are expensive and hence producers may prefer to engage in cooperatives as cooperatives facilitate access to credit to use pesticides and fertilizers.

In comparison with spot market transactions, institutional infrastructure and network specifically distance to asphalt roads influences farmers to participate in cooperative as well as contract engagement. The results showed that a one-kilometer increase in distance from farm to asphalt road increases the probability to sell through the cooperative by $6.5 \%$ and this is significant at the $5 \%$ level. Memberships of farmers group also influence farmers to engage in contracts and also to participate in cooperatives. Farmers' group membership increases the probability of selecting contract engagement as an option for marketing channel by 7.5 percent and significant at $10 \%$ level. Membership of farmers group increases the probability of participation in spot market transactions against cooperative by 4 percent and $10 \%$ significant level. The transfer of knowledge about how to use technology is influenced by the formation of the cooperative. This is because extension agents train farmers through cooperatives. The results show that technology transfer by extension agent increases the probability for a farmer to participate in the cooperative channel by 4.7 percent and this is significant at $10 \%$ level.

Conclusion: This article examines the factors that unravel how the smallholder rice farmers were influenced by contract engagement and cooperative participation against spot market channels for technology acquisition and market access using a sample of 420 rice farmers in southeast Nigeria. The study concluded that the use of agricultural technologies such as chemical fertilizer, improved seeds, agro-chemicals and technical guidance to markets remains low in developing countries due to high transaction costs and other constraints. Technology factors influencing the selection of marketing channels were the use of fertilizer, use of rice seed variety FARO 44, 52, NERICA, long-grain FARO 66, 67. Creation of market linkages, technology and access to credit to smallholders was found to be areas of intervention to improve the rice value chain and to mitigate high transaction costs and technology constraints through contract and cooperatives.

Acknowledgement: The authors sincerely thank the two anonymous reviewers for their helpful comments and suggestions.

\section{REFERENCE}

Abbas, A. M., I. G. Agada, and O. Kolade (2018). Impacts of rice importation on Nigeria's economy. J. Sci. Agri. 2 (1): 71-75. https://doi.org/10.25081/jsa.2018.v2.901

Alemu, A. E. (2015). Technology and market access via contracts and cooperatives for smallholders: Evidence from honey producers in Ethiopia. Afri. J. of Sci. Tech. and Dev., 7(6): 420 - 428. https://doi.org/10.1080/20421338.2015.1096512

Arouna, A., J. C. Lokossou, M. C. S. Wopereis, S. Bruce-oliver, and H. Roy-macauley (2017). Contribution of improved rice varieties to poverty reduction and food security in subSaharan Africa. Glob. Food Sec. 14(August 2016): 54 -60. doi: 10.1016/j.gfs.2017.03.001.

Bernard, T., A. D. Jvanvry, S. Mbaye, and E. Sadoulet (2017). Expected product market reforms and technology adoption by Senegalese. Am. J. of Agri. Econ. 1(1): 20. https://doi.org/10.1093/ajae/aax033

Blanc, B. E., A. Lepine, and E Strobl (2016). Determinants of crop yield and profit of river valley. Exp. Agr., 52(1): 110 -136. https://doi.org/10.1017/S0014479714000581

Chagwiza, C., R. Muradian, and R. Ruben (2016). Cooperative membership and dairy performance among smallholders in Ethiopia. Food Policy. 59(1): 165

-173 . https://doi.org/10.1016/j.foodpol.2016.01.008

Chandio, A. A., and J. Yuansheng (2018). Determinants of Adoption of Improved Rice Varieties in Northern Sindh, Pakistan. Rice Science.25(2): 103-110. https://doi.org/10.1016/j.rsci.2017.10.003

Du, X., Lu, L., Reardon, T., and D. Zilberman (2016). Economics of agricultural supply chain design : a portfolio selection approach. Am. J. of Agri. Econ.O(0):

$1-12$. https://doi.org/10.1093/ajae/aaw074

Ebata, A., P. A. V. Pacheco, and S. V. Cramon-taubadel (2017). The influence of proximity to market on bean producer prices in Nicaragua. Agr. Econ. OO(0): 1-9. https://doi.org/10.1111/agec.12347

Ebata, A., and M. A. Hernandez (2017). Linking smallholder farmers to markets on extensive and intensive margins: Evidence from Nicaragua. Food Policy.73(September): 34-44. https://doi.org/10.1016/j.foodpol.2017.09.003

Federal Ministry of Agriculture and Rural Development (2016). The Agricultural Promotion Policy20162020. Abuja: Federal Ministry of Agriculture and Rural Development. Retrieved fromhttps://fscluster.org/sites/default/files/docu ments/2016-nigeria-agric-sector-policyroadmap june-15-2016 finall.pdf

Harris, B. D. (2018). Intensification benefit index : how much can rural households benefit from agricultural intensification? Exp. Agr. 55(2): 
273-287

https://doi.org/10.1017/S0014479718000042

Jagwe, J. N., and C. Machethe (2016). Effects of Transaction Costs on Choice of Selling Point: A Case of Smallholder Banana Growers in the Great Lakes Region of Central Africa of selling point : a case of smallholder. Agr. Ekon.50(3): 19-123. https://doi.org/10.1080/03031853.2011.617866

Mishra, A. K., A. Kumar, P. K. Joshi, A. D. Souza, and, G.Tripathi (2018). How can organic rice be a boon to smallholders? Evidence from contract farming in India. Food Policy. 75(January): 147157. https://doi.org/10.1016/j.foodpol.2018.01.007

Niang, A., M. Becker, F. Ewert, I. Dieng, T. Gaiser, A. Tanaka, K. Saito (2017). Field Crops Research Variability and determinants of yields in rice production systems of West Africa. Field Crops Res.207(1):

$1-12$. https://doi.org/10.1016/j.fcr.2017.02.014

Ochieng, D. O., P. C. Veettil, and M. Qaim (2017). Farmers ' preferences for supermarket contracts in Kenya. 68, 100-111. https://doi.org/10.1016/j.foodpol.2017.01.008

Opata, P. I. (2018). Determinants of the choice of marketing channel among cocoyam farmers in south-east Nigeria. The J. Anim. Plant Sci. 28(4): 1142-1151. Retrieved from http://www.thejaps.org.pk/

Saito, K., I. Dieng, A. A. Toure, E. A. Somado, and M. C. S. Wopereis (2015). Rice yield growth analysis for 24 African countries over 1960 2012. Glob. Food Sec.5(1): 62-69. https://doi.org/10.1016/j.gfs.2014.10.006

Wossen, T., T. Abdoulaye, A. Alene, M. G. Haile, S. Feleke, A. Olanrewaju, and V. Manyong (2017). Impacts of extension access and cooperative membership on technology adoption and household welfare. J. of Rural Stud. 1(54): 223 233. https://doi.org/10.1016/j.jrurstud.2017.06.022

World Meters (2019). Nigerian population, state by state analysis Retrieved from https://www.worldometers.info/worldpopulation/nigeria-population/. 